\title{
MANAJEMEN LABORATORIUM ILMU PENGETAHUAN ALAM (Tinjauan Khusus Fungsis Manajemen di Sekolah Menengah Pertama Negeri 6 Kota Pekanbaru )
}

\author{
Resti Yolanda ${ }^{1)}$ \\ Azhar ${ }^{2)}$ \\ Marzuki ${ }^{3)}$ \\ ${ }^{1)}$ Post Graduate Student of Riau University \\ ${ }^{2)}$ Lecturer of Education Management Study Programme PPs University of Riau \\ ${ }^{3}$ Lecturer of Education Management Study Programme PPs University of Riau
}

\begin{abstract}
This method aims for the function of laboratory management of Natural Sciences at State Junior High School 6 Pekanbaru City. The type of data of this research is using primary data. Research data were obtained from principals, laboratory heads, and science teachers. Data collection techniques are interviews, observation and documentation. The instrument of this researcher is the researcher himself by applying interview guides, observation checklists, and documentation. Data analysis technique is field analysis and result analysis with process (1) data reduction, (2) data presentation, (3) drawing conclusion. The results of this study indicate that the science of laboratory management in SMP Negeri 6 Pekanbaru City already meet the standard labpratorium IPA, commencement of laboratory facilities that are complete, laboratory conditions adequate although there are still some laboratory space that is not feasible to use, has an organizational structure despite the absence of laboratory labor .
\end{abstract}

Keywords: Management of Natural Science Laboratory, SMP Negeri 6 Pekanbaru City.

\begin{abstract}
ABSTRAK: Metode ini bertujuan untuk fungsi manajemen laboratorium Ilmu Pengetahuan Alam di Sekolah Menengah Pertama Negeri 6 Kota Pekanbaru. Jenis data penelitian ini adalah menggunakan data primer. Data penelitian diperoleh dari kepala sekolah, kepala laboratorium, dan guru IPA. Teknik pengumpulan data adalah wawancara, observasi dan dokumentasi. Instrumen peneliti ini adalah peneliti sendiri dengan menerapkan panduan wawancara, daftar periksa observasi, dan dokumentasi. Teknik analisis data yaitu analisis lapangan dan analisis hasil dengan proses (1) reduksi data, (2) penyajian data, (3) penarikan kesimpulan. Hasil penelitian ini menunjukkan bahwa ilmu manajemen laboratorium di SMP Negeri 6 Kota Pekanbaru sudah memenuhi standar labpratorium IPA, dimulainya fasilitas laboratorium yang sudah lengkap, keadaan laboratorium yang memadai meskipun masih terdapatnya beberapa ruangan laboratorium yang tidak layak digunakan, memiliki struktur organisasi meskipun tidak adanya tenaga laboran.
\end{abstract}

Kata Kunci: Manajemen Laboratorium Ilmu Pengetahuan Alam, SMP Negeri 6 Kota Pekanbaru.

\section{PENDAHULUAN}

Laboratorium sekolah memiliki fungsi yang sangat strategis dalam pencapaian kompetensi siswa. Sebuah laboratoriun di sekolah merupakan hal penting bagi suatu sekolah untuk meningkatkan mutu dan kualitas pendidikan siswa. Dengan adanya laboratorium, diharapkan 1). Siswa bisa lebih mudah memahami materi yang dipelajari sekaligus melakukan praktik. 2). Dapat menunjang proses belajar mengajar agar 
tercapai tujuan pembelajaran, sehingga upaya meningkatkan prestasi siswa semakin meningkat, kenyataanya masih banyak sekolah yang belum memanfaatkan laboratorium sebagai media belajar yang efektif. 3). Mampu meningkatkan minat dan semangat mengajar guru dan belajar siswa. Menurut Nyoman Mastika (2014:2). Laboratorium adalah suatu tempat dilakukan kegiatan percobaan dan penelitian. Tempat ini dapat merupakan ruangan yang tertutup, kamar atau ruangan terbuka.

Menurut Epni Darwita (2013:20) manajemen Laboratorium Ilmu Pengetahuan Alam merupakan suatu bidang ilmu pengetahuan yang sangat berharga dalam upaya peningkatan peserta didik atau siswa untuk meningkatkan kualitas pendidikan dan pengajaran.

Laboratorium Ilmu Pengetahuan Alam di sekolah di manfaatkan untuk penelitian yang dilaksanakan oleh siswa dan guru. Rendahnya pemanfaatan laboratorium Ilmu Pengetahuan Alam di sekolah sebagai salah satu sarana pendukung proses pembelajaran, merupakan salah satu faktorpenghambat dalam peningkatan kemampuan atau keterampilan.

Dengan melaksanakan proses pembelajaran yang memanfaatkan laboratorium atau ruang praktik. Pengelolaan laboratorium Ilmu Pengetahuan Alam dalam proses belajar mengajar harus selalu dalam kondisi siap pakai, keberadaan sarana/media yang ada di dalamnya juga harus dalam keadaan baik serta dilengkapi berbagai administrasi yang efektif.

Berdasarkan observasi awal di Sekolah Menengah Pertama Negeri 6 Pekanbaru, diketahui bahwa Sekolah Menengah Pertama Negeri 6 Pekanbaru berdiri pada tahun 1974, pada tahun tersebut sekolah menengah pertama negeri 6 bernama SMP mutiara secara deskriptif SMP mutiara memiliki luas tanah 4,5 hektar dengan memiliki ruangan berjumlah 29 ruangan yang terdiri dari jumlah kelas 7 yaitu sebanyak 8 kelas, kelas 8 berjumlah 9 kelas, kelas 9 berjumlah 9 kelas, ruang majelis guru berjumlah 1 ruang, laboratorium IPA berjumlah 1 ruang dan perpustakaan berjumlah 1 ruang.
SMP mutiara ini berumur 3 tahun setelah smp mutiara di tukar namanya menjadi Sekolah Menengah Pertama Negeri 6 Pekanbaru. Hingga pada tanggal 31 Agustus 2010 Sekolah Menengah Pertama Negeri 6 Pekanbaru mengalami kebakaran hingga banyak ruangan beserta kelas terbakar. Kebakaran telah menghanguskan 22 ruangan sekolah. Terdiri dari 14 kelas, laboratorium IPA, ruang majelis guru, dan kantor kepala sekolah.

Berdasarkan fenomena tersebut fungsi laboratorium IPA di Sekolah Menengah Pertama Negeri 6 Pekanbaru kurang terlaksana dengan baik, proses pelaksanaan kegiatan di laboratorium tidak efisien serta fungsi administrasi manajemen laboratorium tidak teratur, dan adanya keterbatasan perlengkapan peralatan yang ada di laboratorium IPA. Laboratorium IPA Sekolah Menengah Pertama Negeri 6 pekanbaru perlu dikaji secara ilmiah melalui penelitian yang berjudul Manajemen Laboratorium Ilmu Pengetahuan Alam Tinjauan Khusus Fungsi Manajemen di Sekolah Menengah Pertama Negeri 6 Pekanbaru. .

Fokus dalam penelitian ini yaitu Bagaimana pengelolaan laboratorium ipa sekolah menengah pertama negeri 6 Pekanbaru. Sedangkan subfokus adalah :

1. Bagaimana perencanaan program kerja laboratotium ilmu pengetahuan alam tinjauan khusus fungsi manajemen Sekolah Menengah Pertama Negeri 6 Pekanbaru?

2. Bagaimana pengorganisasian laboratorium ilmu pengetahuan alam tinjauan khusus fungsi manajemen Sekolah Menengah Pertama Negeri 6 Kota Pekanbaru?

3. Bagaimana pelaksanaan program kerja laboratorium ilmu pengetahuan alam tinjauan khusus fungsi manajemen Sekolah Menengah Pertama Negeri 6 Kota Pekanbaru?

4. Bagaimana pengawasan laboratorium ilmu pengetahuan alam tinjauan khusus fungsi manajemen Sekolah Menengah Pertama Negeri 6 Kota Pekanbaru?

5. Adakah faktor pendukung dan penghambat dalam pelaksanaan manajemen laboratorium 
ilmu pengetahuan alam di Sekolah Menengah Pertama Negeri 6 Kota Pekanbaru?

Kegunaan Penelitian secara teoretis dari hasil penelitian diharapkan dapat dijadikan rujukan bagi pengelolaan dalam melaksanakan fungsi manajemen laboratorium di Sekolah Menengah Pertama Negeri 6 Pekanbaru. Penelitian ini hendaknya memberikan sumbangan berupa pengetahuan, data atau informasi yang memadai dalam rangka perkembangan ilmu manajemen pendidikan atau salah satu konsep pengembangan ilmu pengetahuan khususnya bidang efektifitas pengelolaan laboratorium Sekolah Memengah Pertama Negeri 6 Pekanbaru.Kegunaan penelitian secara praktik.Hasil penelitian ini juga diharapkan memberikan manfaat praktis yaitu memberikan sumbangan pemikiran bagi sekolah dalam menyiasati pengelolaan laboratorium ilmu pengetahuan alam, sehingga proses belajar mengajar dan praktik di laboratorium ilmu pengetahuan alam Sekolah Menengah Pertama Negeri 6 Pekanbaru dapat menuju hasil yang lebih efektif.

\section{METODOLOGI PENELITIAN}

Penelitian ini dilaksanakan di SMP Negeri 6 Kota Pekanbaru yang berlokasi di Jalan Yos Sudarso. Waktu penelitian ini dilaksanakan selama 3 bulan yaitu pada bulan Maret hingga Mei 2017.

Berdasarkan tujuan penelitian ini, maka penelitian ini menggunakan pendekatan deskriptif kualitatif.

Sebelum peneliti melakukan pemilihan informan, maka terlebih dahulu ditetapkan situasi sosial yang merupakan tempat dimana permasalahan atau fenomena sosial yang akan diteliti betul-betul ada. Untuk mendapatkan informasi yang benar valid, maka di dalam memilih informasi dapat dilakukan melalui wawanvara pendahuluan, sebelum melakukan penelitian. Informan dalam penelitian ini adalah kepala sekolah, kepala laboratorium, dan guru matapelajran IPA.
Dalam penelitian ini untuk mengumpulkan data penulis akan menggunakan alat sebagai berikut : wawancara, Observasi, dan Dokumentasi.

Dalam penelitian ini analisis data yang digunakan yaitu semua yang terjadi, baik yang direncanakan maupun tidak direncanakan perlu dianalisis untuk melihat bagaimana pengelolaan laboratorium khususnya dalam hal perencanaan, pengorganisasian, pelaksanaan.

Data yang dikumpulkan melalui observasi dan wawancara akan dianalisis melalui dua tahap yaitu Analisis Lapangan: dilakukan oleh peneliti saat pengamatan dan proses pengambilan data. Analisi lapanganmemungkinkan penyederhanaan berupa catatan pertanyaan yang diajukan pada subjek penelitian. Analisis Hasil Dilakukan setelah data terkumpul. Analisis hasil dilakukan dalam tahap-tahap berikut yaitu: (1) reduksi data, (2) penyajian data, (3) penarikan kesimpulan (menurut Miles dan Huberman, 1992 : 16).

Untuk menjaga keabsahan pada penelitian ini, penulis melakukan observasi dan wawancara serta studi dokumentasi. Diharapkan dengan melakukan beberapa kegiatan tersebut data yang diperoleh dapat terjaga keabsahannya. Ada empat kriteria yang digunakan yaiu, perpanjangan pengamatan, peningkatan ketekunan, triangulasi dan pengujian keabsahan data.

\section{HASILDANPEMBAHASAN}

\section{A. Visi, Misi dan Tujuan Laboratorium SMP Negeri 6 Kota Pekabaru}

Visi laboratorium SMP Negeri 6 Kota Pekanbaru yaitu laboratorium IPA sebagai sarana peserta didik dan pendidik dalam proses pembelajaran melalui pratikum atau penelitian yang akan menimbulkan rasa ingin tahu sehingga membentuk peserta didik yang disiplin dan tanggung jawab, kreatif motivatif dan religius.

Misi laboratorium SMP Negeri 6 Kota Pekanbaru yaitu membangun suasana laboratorium IPA yang nyaman, membangun dan mengembangkan kecakapan siswa dalam berpraktikum/ penelitian sehingga kelak peserta didik mampu berkreatif dan inovatif dalam belajar IPA, memberikan pelayanan pendidikan kepada 
siswa dengan mutu setinggi mungkin, meningkatkan layanan laboratorium sebagai pusat kegiatan penunjang akademik / pratikum, penelitian bidang pendidikan IPA. Adapun tujuan dari laboratorium SMP Negeri 6 Kota Pekabaru yaitu:1) menciptakan suasana laboratorium IPA yang nyaman, 2) membangun dan mengembangkan kecakapan siswa dalam berpratikum / penelitian sehingga kelak peserta didik mampu berkreatif dan inovatif dalam belajar IPA, 3) memberikan pelayanan pendidikan kepada siswa dengan mutu setinggi mungkin, 4) meningkatkan layanan laboratorium sebagai pusat kegiatan penunjang akademik / pratikum, penelitian dalam bidang IPA.

1. Sub Fokus 1 : Perencanaan Manajemen Laboratorium SMP Negeri 6 Kota Pekanbaru dilihat dari sarana dan prasarana, penggunaan alat dan bahan laboratorium, dana laboratorium.

Berdasarkan hasil peneltian sarana dan prasarana laboratorium IPA di SMP N egeri 6 Kota Pekanbaru memiliki 3 ruanagan laboratorium yaitu laboratorium kelas VII, Laboratorium Kelas VIII, berada di belakang sekolah dan sudah tidak layak pakai dan Laboratorium kelas IX terletak di depan sekolah, kondisi ruangan layak digunakan, namun masih terdapat beberapa fasilitas yang tidak tersedia di laboratorium. Ketersediaan alat dan bahan laboratorium cukup, namun masih terdapat beberapa alat yang tidak ada disaat pelaksanaan pratikum. Untuk mengatasi hal tersebut guru mata pelajaran akan memberikan penugasan kepada siswa untuk membawa bahan yang akan digunakan saat pratikum dari rumah masingmasing. Dana pengelolaan laboratorium berasal dari dana pemerintah Kota Pekanbaru dan dana dari PT. Caltex, namun sudah tujuh tahun lamanya bantuan dana dari PT. Caltex sudah tidak ada lagi.

2. Sub Fokus 2 : Proses dilihat dari program kerja laboratorium IPA dalam pengorganisasian laboratorium IPAdi SMP Negeri 6 Kota Pekanbaru.

Berdasarkan hasil penelitian menunjukkan bahwa organisasi laboratorium IPA
SMP Negeri 6 Kota Pekanbaru cukup lengkap, dimulai dari kepala sekolah, waka kurikulum, kepala laboratorium, pengelola, guru mata pelajaran dan siswa. Tetapi tidak adanya laboran di struktur organisasi laboratorium IPA SMP Negeri 6 Kota Pekanbaru.

3. Sub Fokus 3 : Pelaksanaan program kerja laboratorium IPA dilihat dari pengadaan alat dan bahan laboratorium, perawatan / pemeliharaan alat laboratorium, pengecekan dan perbaikan alat laboratorium, administrasi laboratorium dan kegiatan pratikum.

Berdasarkan hasil penelitian menunjukkan bahwa pengadaan alat dan bahan laboratorium dilakukan oleh kepala laboratorium dan mengajukan alat dan bahan yang akan diperlukan ke kepala sekolah, perawatan/ pemeliharaan alat laboratorium dilakukan oleh seluruh para peserta didik yang telah selesai melaksanakan pratikum dan dibantu oleh guru mata pelajaran IPA, untuk kelengkapan administrasi laboratorium sudah di buat oleh kepala laboratorium dan tertera di dalam program kerja tahunan. Inventaris alat dan bahan laboratorium sudah disusun dan buat oleh kepala laboratorium. Jadwal kegiatan pratikum disusun oleh kepala laboratorium berdasarkan jadwal mata pelajaran dari setiap masing-masing kelas.

\section{Sub Fokus 4 : Pengawasan laboratorium.}

Berdasarkan hasil pengamatan pengawasan dilakukan oleh kepala sekolah dan pengawas dari Dinas Pendidikan Kota Pekanbaru. Untuk pengawasan tidak tentu dilaksanakan waktunya terkadang disetiap awal semester atau di akhir semester.

5. Sub Fokus 5 : Faktor pendukung dan Penghambat kinerja di laboratorium IPA SMP Negeri 6 Kota Pekanbaru.

Berdasarkan hasil penelitian faktor pendukung pada laboratorium IPA SMP Negeri 6 Kota Pekanbaru tidak ada namun dapat dilihat dari bentuk gedung yang baikdan sudah memnuhi standar dari laboratorium IPA Sekolah Menengah Pertama. Untuk faktor penghambat 
dari laboratorium IPA di SMP Negeri 6 Kota Pekanbaru yaitu dapat dilihat dari fasilitas alat dan bahan yang masih kurang, sumber dana untuk fasilitas alat dan bahan yang di laboratorium IPA, tenaga laboran yang tidak ada.

1. Sub Fokus 1 : Perencanaan Manajemen Laboratorium SMP Negeri 6 Kota Pekanbaru dilihat dari sarana dan prasarana, penggunaan alat dan bahan laboratorium, dana laboratorium.

Berdasarkan hasil ternyata sarana dan prasarana yang ada di laboratorium IPA SMP Negeri 6 Kota Pekanbaru secara umum belum begitu memadai dan belum begitu lengkap. Kondisi fisik gedung sudah memenuhi standar hanya saja gedung untuk laboratorium masih satu yang bisa digunakan sedangkan dua gedung lagi tidak bisa digunakan karena fasilitas yang kurang memadai semenjak terjadinya kebakaran. Sarana dan prasarana yang ada di laboratorium belum sepenuhnya terpenuhi terlihat pada masingmasing tempat penyimpanan alat-alat masih perlu banyak penambahan dan perbaikan seperti penambahan lemari penyimpanan sehingga alatalat yang disimpan masih banyak yang berdebu.

Kelengkapan alat-alat dan bahan masih perlu banyak penambahan karena kebutuhan alat dan bahan yang ada di laboratorium SMP Negeri 6 Kota Pekanbaru tidak semuanya dapat terpenuhi. Ruanagan laboratorium kelas VII dan VIII dalam keadaan kurang berfungsi dikarenakan keadaan ruangan beserta fasilitas perlengkapan labor seperti meja, kursi tidak memadai dalam keadaan rusak. Sedangkan, ruangan laboratorium IX di SMP Negeri 6 Kota Pekanbaru sudah memiliki peralatan yang cukup lengkap mulai dari meja dan kursi praktikum untuk masing-masing siswa, tempat cuci pirirng, jaringan listrik. Hanya saja peralatan yang lengkap tersebut masih ada yang belum bias dipergunakan seperti tempat cuci piring dan jaringan listrik.

Fasilitas lain yang dimiliki diantaranya alatalat kebersihan ruangan lengkap, sirkulasi udara dalam ruangan sangat baik, 1 buah P3K. Alatalat dan bahan untuk praktikum sudah tersusun rapi. Sebagian alat dan bahan ada yang tidak dilengkapi nama. 2. Sub Fokus 2 : Proses dilihat dari program kerja laboratorium IPA dalam pengorganisasian laboratorium IPA di SMP Negeri 6 Kota Pekanbaru. Depdikbud (1999:17) menyatakan bahwa mekanisme kerja dalam pengorganisasian laboratorium sebaiknya Kepala sekolah, sebagai EMAS (Educator, Management, Administator, and Supervisor) memberikan arahan pengelolaan laboratorium IPAyang meliputi teknis pengelolaan laboratorium kepada koordinator pengelolaan laboratorium, penanggung jawab laboratorium, guru-guru IPA, teknisi alat IPA ( bagi sekolah yang sudah ada ) dan laboran laboratorium IPA. Administrasi laboratorium IPA kepada Kepala tata usaha dan staf tata usaha yang ditugaskan dan Laboran laboratorium. Pada laboratorium IPA SMP Negeri 6 kota Pekanbaru pembagian struktur organisasinya belum terkoordinasi, karena hanya melibatkan kepala sekolah, kepala labortorium, guru mata pelajaran serta guru mata pelajaran, namun untuk laboran belum mempunyai tenaga khusus dalam pengelolaan laboratorium. Pada penyusunan organisasi tidak tercantum wakil kepala sekolah bidang sarana dan prasarana serta penanggung jawab teknis dalam pengelolaan laboratorium.

Tenaga laboranya diambil dari guru yang mengajar mata pelajaran ipa di kelas IX dan juga sebagai kepala laboratorium. Untuk kepala labolatorium belum dapat melaksanakan tugasnya dengan baik karena keterbatasan waktu dan tenaga. Kepala labolatorium merupakan guru yang mengajar mata pelajaran IPA di kelas IX dengan jadwal mengajar yang padat.

Pembagian surat tugas ini dibuat pada awal tahun dan dibuat setiap semester. Tetapi kalau tidak ada perubahan maka surat tugas tersebut biasa berlaku sampai satu tahun atau dua semester. Kualifikasi tenaga pendidikan untuk kepala labolatorium adalah sarjana (S1) dan pengelola labolatorium dengan pendidikan (S1). Kepala labolatorium maupun mengajar mata pelajaran IPA kelas IX, sedangkan pengelola laboratorium mengajar di kelas VII dan VIII.

3. Sub Fokus 3 : Pelaksanaan program kerja laboratorium IPAdilihat dari pengadaan alat dan bahan laboratorium, perawatan / pemeliharaan alat laboratorium, pengecekan dan 
perbaikan alat laboratorium, administrasi laboratorium dan kegiatan pratikum.

Depdikbud (1996:19) menyatakan bahwa kegiatan pengadaan bertujuan untuk memperoleh alat dan bahan menurut rencana kebutuhan yang telah di tentukan. Berdasarkan tata cara yang ada maka pengadaan alat dan bahan dapat dilakukan dengan jalan: a)membeli, b) menerima bantuan / sumbangan baik dari pemerintah maupun masyarakat, c) membuat sendiri, d) menyewa. Dalam melaksanakan pengadaan alat dan bahan perlu di perhatikan antara lain hal-hal sebagai berikut : a) kebutuhan alat dan bahan, b) anggaran yang tersedia, c) sumber alat dan bahan.

Hanya saja hasil observasi yang dilakukan di SMP Negeri 6 kota Pekanbaru ternyata untuk proses pengadaan alat da bahan yang diterima terakhir tahun 2010 yang pada waktu itu kepala sekolah dijabat oleh Mei Supriatin, S.Pd dan bantuan yang diberikan berasal dari PT. Caltex yang bertempat di Rumbai, Pekanbaru. Sesuai hasil wawancara dengan kepala laboratorium menunjukkan bahwa : jika ada alat yang rusak selama melaksanakan kegiatan praktikum oleh siswa tindakan tindakan yang dilakukan guru adalah menugaskan siswa menggantinya secara bersama-sama, tetapi kalau alat yang digantikan tersebut mahal harganya maka akan dicarikan jalan lain”.Pemeliharaan alat dan bahan praktikum setelah selesai di gunakan melibatkan siswa yang di bimbing oleh guru. penyimpanan alat-alat dan bahan perlu lebih dimaksimalkan kembali sehingga dapat menunjang proses belajar dengan baik.

Laboratorium SMP Negeri 6 Kota Pekanbaru sudah memenuhi syarat-syarat sebuah laboratorium dalam mengurangi terjadinya kecelakaan kerja. Antisipasi sudah dilakukan oleh pihak sekolah walaupun dengan peralatan seadanya. Selanjutnya pengelola laboratorium ilmu pengetahuan alam hendaknya mempunyai pengetahuan tentang Pertolongan Pertama Pada Kecelakaan (PPPK). Untuk keamanan di SMP Negeri 6 Kota Pekanbaru cukup aman dalam hal-hal pencurian dan pengrusakan.
Dari hasil dokumentasi dapat kelengkapan administrasi laboratorium IPA SMP Negeri 6 kota Pekanbaru sebagai berikut :

1. Program tahunan : disusun oleh kepala laboratorium bekerja sama dengan pengelola laboratorium. Program tahunan dibuat setiap awal tahun pelajaran yang berisi mengenai kegiatan dalam laboratorium.

2. Denah laboratorium : ada dan terdapat di dalam program kerja laboratorium.

3. Struktur organisasi : ada didalam ruangan laboratorium.

4. Buku inventaris : ada dan berisi mengenai inventaris alat-alat dan bahan pratikum.

5. Tata tertib : ada dalam ruangan laboratorium dan ditempelkan didinding laboratorium dan tata tertib laboratorium juga tertera dalam program tahunan.

6. Jadwal penggunaan laboratorium : ada, tertera di dalam program kerja laboratorium.

7. Buku pegangan guru : cukup lengkap terdiri dari kelas VII,VIII dan IX

8. Alat - alat dan bahan yang digunakan : kurang lengkap, karena ada beberapabahan yang digunakan habis terpakai.

9. Media pembelajaran : ada cukup lengkap, yang terdiri dari chart ( gambar) dan torso.

10. Buku daftar pembelian barang : ada, diisi oleh sekolah mengenai alat - alat dan bahan yang dibeli dari dana sekolah.

\section{Sub Fokus 4 : Pengawasan laboratorium.}

Berdasarkan hasil wawancara oleh kepala laboratorium IPA yaitu pengawasan dilakukan Pengawasan dilaksanakan oleh pengawas dari dinas pendidikan kota Pekanbaru bersama kepala sekolah. Dilakukannya pengawasan untuk mengetahui kinerja para seluruh anggota yang termasuk dalam organisasi laboratorium baik itu dari hasil kinerja pengawasan pratikum maupun dari hasil program kerja yang telah disepakati bersama dan pengawasan ini tidak menentu, terkadang dilaksanakan setiap awal semeeter dan akhir semester.

Hal tersebut juga dijelaskan oleh guru mata pelajaran IPA kelas VIII bahwasannya 
laboratorium diawasi oleh kepala sekolah dan pengawas dari Dinas Pendidikan Kota Pekanbaru. Pengawas tersbeut melihat kinerja dari seluruh anggota pengelola organisasi laboratorium dalam waktu yang tidak ditentukan. Dalam pengawasan tersebut selalu diberikannya motivasi untuk perkembangan laboratorium IPA SMP Negeri 6 Kota Pekanbaru.

5. Sub Fokus 5 : Faktor pendukung dan Penghambat kinerja di laboratorium IPA SMP Negeri 6 Kota Pekanbaru.

Faktor-faktor yang menjadi pendukung didalam pengelolaan laboratorium sekolah belum ada karena alat-alat dan bahan yang digunakan merupakan alat-alat yang sudah lama dan perlu dilakukan peremajaan kembali, dari hasil observasi terlihat bahwa faktor pendukung hanya pada sebuah bangunan yang memenuhi standar dalam melakukan praktikum.

Hasil observasi yang peneliti lakukan terhadap faktor-faktor pendukung dan penghambat didalam pengelolaan laboratorium IPA SMP N 6 Kota Pekanbaru ternyata bahwa terdapat banyak sekali faktor-faktor penghambat yang ada terutama yang paling menonjol adalah pengadaan alat-alat dan bahan yang belum mencukupi untuk kebutuhan praktikum siswa. Hal ini dikarenakan bantuan yang tidak sepenuhnya diterima oleh pihak sekolah, sementara pengajuan usulan alat dan bahan sering dilakukan oleh pihak sekolah hanya saja dari bantuan Caltex, ini terlihat dari bantuan yang diterima awal SMP Negeri 6 dibangunselanjutnya dari tahun 2010 sampai sekarang tidak pernah menerima bantuan alat-alat laboratorium.

Masalah selanjutnya yang dihadapi adalah ketersediaan dana yang sama sekali tidak mencukupi untuk pembelian alat dan bahan sedangkan alat dan bahan untuk laboratorium sangat mahal untuk ukuran dana sebuah sekolah.

Berdasarkan hasil wawancara oleh kepala laboratorium dalam mengatasi hambatan terhadap pelaksanaan kegiatan pratikum yaitu guru menyuruh siswa untuk membawa alat dan bahan yang akan digunakan untuk pratikum yang sudah tidak tersedia di laboratorium dan guru membeli alat dan bahan terlebih dahulu menggunakan dana sendiri sebelum nantinya diganti oleh pihak sekolah.

\section{SIMPULAN DAN SARAN}

1. Perencanaan laboratorium IPA masih belum dilaksanakan secara optimal seperti kebutuhan alat-alat dan bahan yang masih kurang, pendanaan laboratorium yang masih minim dan bergantung dari bantuan yang diberikan oleh pemerintah dan instansi lainya, sarana dan prasarana yang masih perlu banyak ditingkatkan dan ruangan laboratorium yang terpisah dan masih ada nya ruang laboratorium yang tidak bisa dipergunakan dengan baik hal ini disebabkan karena kekurangannya fasilitas yang tidak memadai.

2. Implementasi perencanaan laboratorium IPA masih kurang tersusun dengan baik, program kerja di laboratorium yang ada hanya jadwal penggunaan laboratorium, program tahunan, inventaris laboratorium, tata tertib laboratorium.

3. Pengawasan laboratorium sudah dilaksanakan secara baik dengan cara penilaian yang dilaksanakan oleh kepala sekolah maupun pegawas dari dinas pendidikan Kota Pekanbaru.

4. Faktor-faktor pendukung yang ditemui dalam pengelolaan laboratorium IPA di SMP Negeri 6 Kota Pekanbaru hanya ada pada gedung dan bantuan alat-alat yang diterima walaupun bantuan tersebut hanya sekali diberikan. Faktor penghambatnya adalah pada sarana dan prasarana, pendanaan yang minim, tenaga laboran yang bukan merupakan dari tenaga khusus yang sesuai dengan bidang tugasanya.

\section{Saran}

1. Kepala sekolah beserta kepala laboratorium, dan guru mata pelajaran IPA hendaknya agar lebih cepat mewujudkan indikator yang akan diharapkan sehingga mampu memberikan gambaran karakteristik laboratorium yang diinginkan di masa datang 
2. Dana untuk pengadaan dan alat untuk praktikum perlu diperbesar lagi terutama pendanaan dari pihak sekolah.

3. Perlu adanya tenaga khusus dalam mengelola laboratorium yang memiliki keterampilan sesuai dengan bidang tugas.

4. Pengelola laboratorium agar lebih diberdayagunakan didalam mengikti pelatihan-pelatihan atau keterampilan guna meningkatkan wawasanya dalam mengelola laboratorium.

5. Kepala sekolah perlu lebih meningkatkan pembinaan kepada pengelola laboratorium dalam upaya meningkatkan kualitas sekolah.

\section{DAFTAR PUSTAKA}

Amien. 1988. Prosedur Laboratorium. Jakarta : Rineka Cipta

Alwi. 1993. Landasan Manajemen. Bandung : PT. Remaja Rosdakarya

Arikunto, Suharsimi. 2002. Prosedur Penelitian Suatu Pendekatan Praktek. Jakarta : Rineka Cipta

Arikunto, Suharsimi. 2009. Manajemen Penelitian. Jakarta : Rineka Cipta

Didin Kurniadin. 2014. Manajemen Pendidikan. Jakarta : Ar-Ruzz Media

Depdiknas, 2005. Standar Minimal Laboratorium Pendidikan teknologi dan Kejurusan, Direktorat Pembinaan Pendidikan Tenaga Kependidikan dan Ketenagaan Perguruan Tinggi.

Depdiknas . 2003. Standar Kompetensi Mata Pelajaran Sains Sekolah Menengah Pertama dan Madrasah Tsanawiyah, Jakarta : Depdiknas.

Depdikbud. 1996. Manajemen Perawatan Preventif SLTP. Direktorat Jenderal Pendidikan Dasar dan Menengah Jakarta.
Epni Darwita. 2013. Tesis Pengelolaan Laboratorium Ilmu Pengetahuan Alam. Unibersitas Bengkulu

George R.Terry, 1992. Dasar - dasar Manajemen. Bumi Aksara

Handoko, T.H. 2003. Manajemen. Yogyakarta: BPEE-UGM

Handayadiningrat. 1980. Kebijakan Manajemen. Jakarta : Tiga Serangkai

Husaini Usman. 2013. Manajemen. Jakarta : Bumi Aksara

Malayu Hasibuan. 2000. Manajemen Sumber Daya Manusia. Jakarta : Bumi Aksara.

Mattew B. Miles. 1992. Analisis Data Kualitatif. Jakarta : Universitas Indonesia Manullang. 1988. Dasar-dasar Manajemen. Medan: Ghalia Indonesia.

Nanang Fattah. 2009. Landasan Manajemen Pendidikan. Bandung : PT. Remaja Rosdakarya

Peraturan Pemerintah. No. 5 Tahun 1980

Peraturan Pemerintah No. 24 Tahun 2007

Prawirohartono Slamet. 2014. Ilmu Pengetahuan Alam. Jakarta : Bumi Aksara Riskiono Prawirohartono. 2004. Pengelolaan Laboratorium. Jakarta : Bumi Aksara Siagian, Sondang, P. 2003. Filsafat Administrasi. Jakarta: PT. Bumi Aksara

Siswanto. 1990. Dasar Manajemen. Bandung :PT. Remaja Rosdakarya

Slamet. 2014. Tata Cara Penggunaan Laboratorium. Jakarta : Rhineka Cipta

Sukardjo. 2014. Ilmu Pengetahuan Alam. Jakarta : Bumi Aksara

Terry, George . R. \& Rue, Leslie.W. 2005. Dasar-dasar Manajemen. Penerjemah Ticoalu. Jakarta : PT. Bumi Aksara. 